\title{
Slik måler du blodtrykk på barn
}

Både menneskelige og tekniske feil forekommer relativt hyppig ved blodtrykksmålinger. Feilmålinger av blodtrykk hos barn ka n føre til unødvendig utredning og behandling.

\section{Forfattere}

\section{Erlend Johnsen}

Spesialsykepleier

Barne- og ungdomsklinikken, Haukeland universitetssjukehus

\section{Gottfried Greve}

Overlege og professor

Barne- og ungdomsklinikken, Haukeland universitetssjukehus og Universitetet i Bergen

\section{Ansgar Berg}

Overlege og professor

Barne- og ungdomsklinikken, Haukeland universitetssjukehus og Universitetet i Bergen

\section{Kjersti Oterhals}

Fag- og forskningssykepleier og førsteamanuensis

Hjerteavdelingen, Haukeland universitetssjukehus og Høgskulen på Vestlandet

\section{Nøkkelord}

Blodtrykk Barn

Sykepleien 2018 106(729)(e-0729)

DOI: https://doi.org/10.4220/Sykepleiens.2018.70729

\section{HOVEDBUDSKAP}

Måling av blodtrykk (BT) er en billig, non-invasiv undersøkelse for å påvise hypertensjon (HT) hos barn. Selv om BT-måling er anbefalt rutineunders $\emptyset$ kelse i sykehus fra tre års alder, blir dette ofte ikke gjennomført. Det målte BT er en viktig parameter for beslutning om videre utredning eller evaluering av behandling. BT-måling hos barn er imidlertid en prosedyre med mange feilkilder, som gjør at BT-målinger ofte blir en upålitelig parameter i klinisk medisin. 
Barn over tre år som får medisinsk oppfølging eller behandling, bør måle BT ved hver kontakt med sykehus for å avdekke HT $(1,2)$. HT er viktig å identifisere hos barn siden underliggende patologi krever utredning og behandling. Feilmålinger av BT hos barn vil kunne ha alvorlige konsekvenser og føre til unødvendig utredning og behandling.

Manuell auskultatorisk målemetode er anbefalt på barn (1-3), mens automatisk oscillometrisk målemetode av praktiske årsaker er foretrukket de fleste steder. Begge metodene kan være forbundet med feilmålinger, hvor menneskelige og tekniske feil forekommer relativt hyppig (3).

Manuell auskultatorisk BT-måling med Scipione RivaRoccis kvikksølvmanometer ble introdusert i Italia i 1896 og har ikke endret seg vesentlig siden den russiske kirurgen Nikolai Korotkoff beskrev metoden i 1905 (4). Korotkoff auskulterte en arterie distalt for en oppblåst mansjett på pasientens overarm mens luften ble sluppet ut av mansjetten, og hørte de såkalte Korotkoff-lydene, som han klassifiserte i fem faser: K1-K5 (5). Se tabell 1. K1 brukes til å registrere systolisk BT (SBT), mens K5 brukes til å registrere diastolisk BT (DBT) $(1,3)$. Metoden er fortsatt gullstandarden.

$\begin{array}{ll}\text { Fase } & \text { Beskrivelse } \\ \text { K1 } & \text { Klar, tydelig lyd som samsvarer med palpabel puls } \\ \text { K2 } & \text { Vedvarende, men svakere lyd } \\ \text { K3 } & \text { Lyden blir tydeligere, men kortere } \\ \text { K4 } & \text { Lyden blir tydelig svakere } \\ \text { K5 } & \text { Lyden forsvinner }\end{array}$


Non-invasiv BT-måling gjøres i dag i hovedsak ved bruk av to metoder, manuell auskultatorisk (heretter kalt auskultatorisk) og automatisk oscillometrisk (heretter kalt automatisk). Aneroide sphygmomanometre har tatt over for kvikksølvmanometre når BT måles auskultatorisk på grunn av kvikksølvets toksisitet (3). Dersom riktig mansjettstørrelse blir brukt (1-3, 6-8) og sphygmomanometeret blir kalibrert mot et kvikksølvmanometer hver sjette måned $(1,3,8)$, regnes disse som svært nøyaktige.

Automatiske BT-målere har økt i bruk de siste årene. Få av disse er validert og godkjent for bruk til barn (1, 2). På den andre siden eliminerer de en av de største feilkildene ved auskultatorisk metode: menneskelige feil $(3,9)$.

\section{Forberedelse}

Forberedelse av barnet kan påvirke BT-målingen like mye som tekniske faktorer (1). Noen forhold kan virke inn på målingen uavhengig av hvilken metode som brukes: romtemperatur, nikotininntak (kan være aktuelt hos ungdom), armposisjon, muskelspenning, prating og bakgrunnsstøy er eksempler på slike forhold (3).

Barnet skal instrueres om ikke å prate under målingen (3). For å hindre bakgrunnsstøy gjelder det samme for foreldrene og den som måler. En studie der sykepleiere ble observert når de målte BT på voksne pasienter, viste at prating under målingen var den hyppigste feilkilden (10).

\section{三 «orberedelse av barnet kan påvirke blodtrykksmålingen like mye som tekniske faktorer.»}


Å la barnet få se og kjenne på mansjetten samtidig som prosedyren blir forklart, kan være med på å gjøre opplevelsen bedre for barnet. Hos barn som er urolige og gruer seg til å måle BT, kan en plassere mansjetten på barnets overarm etter å ha forklart prosedyren, før en lar foreldrene trøste og roe barnet ved å synge en sang eller se i en bok.

Når barnet er rolig, kan målingen utføres. Å la en av foreldrene støtte armen til barnet, uten å holde hardt fast, er også et godt råd (3).

\section{Kroppsposisjon}

Barnet skal sitte med støtte for rygg. Begge føtter skal hvile på gulvet eller på en krakk uten at beina er i kryss. Armen skal være i en posisjon hvor midten av mansjetten er i hjertehøyde, tilsvarende høyre forkammer, som blir omtrent midt på sternum eller fjerde intercostalrom $(1,3)$. Dersom barnet må ligge under målingen, må armen støttes opp med en pute eller liknende, slik at mansjetten er i hjertehøyde (3). 


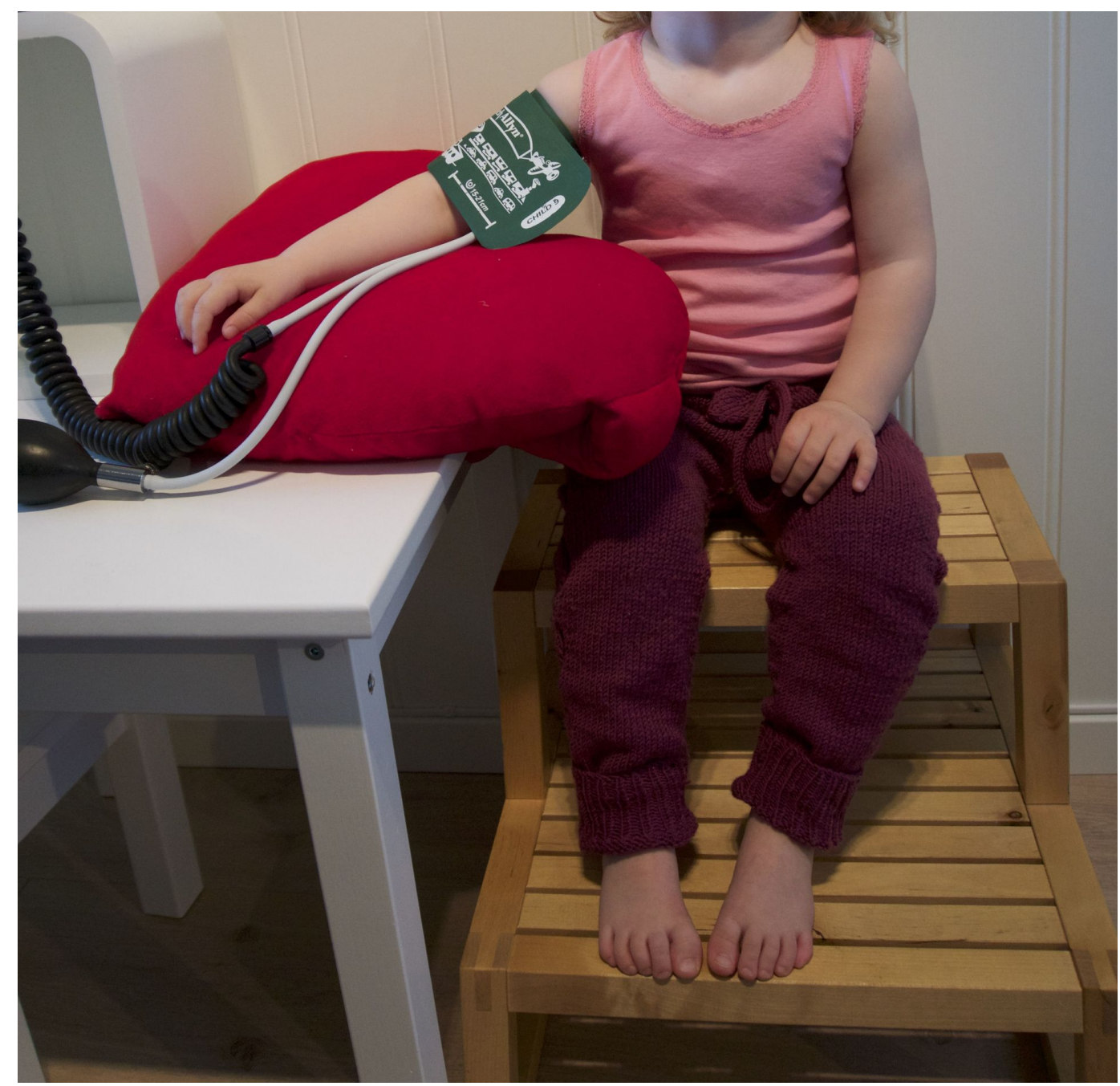

RIKTIG SITTESTILLING: Barnet skal sitte med støtte for rygg. Begge føtter skal hvile på gulvet eller på en krakk uten at beina er i kryss. Foto: Privat

\section{Mansjettstørrelse}

Den ideelle mansjetten har en blære hvis bredde dekker minst 40 prosent av lengden på overarmen målt fra skulderhøyden til albuen (acromion-olecranon), og en lengde som dekker 80-100 prosent av overarmens omkrets målt midt på overarmen $(1,3)$. BT kan bli overestimert med for liten mansjett og underestimert med for stor mansjett (1).

De fleste mansjetter er utstyrt med hjelpemidler for raskt å kunne si om de passer til barnet. Et av disse er hvilken armomkrets de passer til. Det kan være nyttig å ha et målebånd tilgjengelig, slik at armomkrets kan måles nøyaktig. Dersom størrelsen på armen passer med to mansjetter, skal den største velges fordi en for liten mansjett kan overestimere mer enn en for stor mansjett kan underestimere (1). 


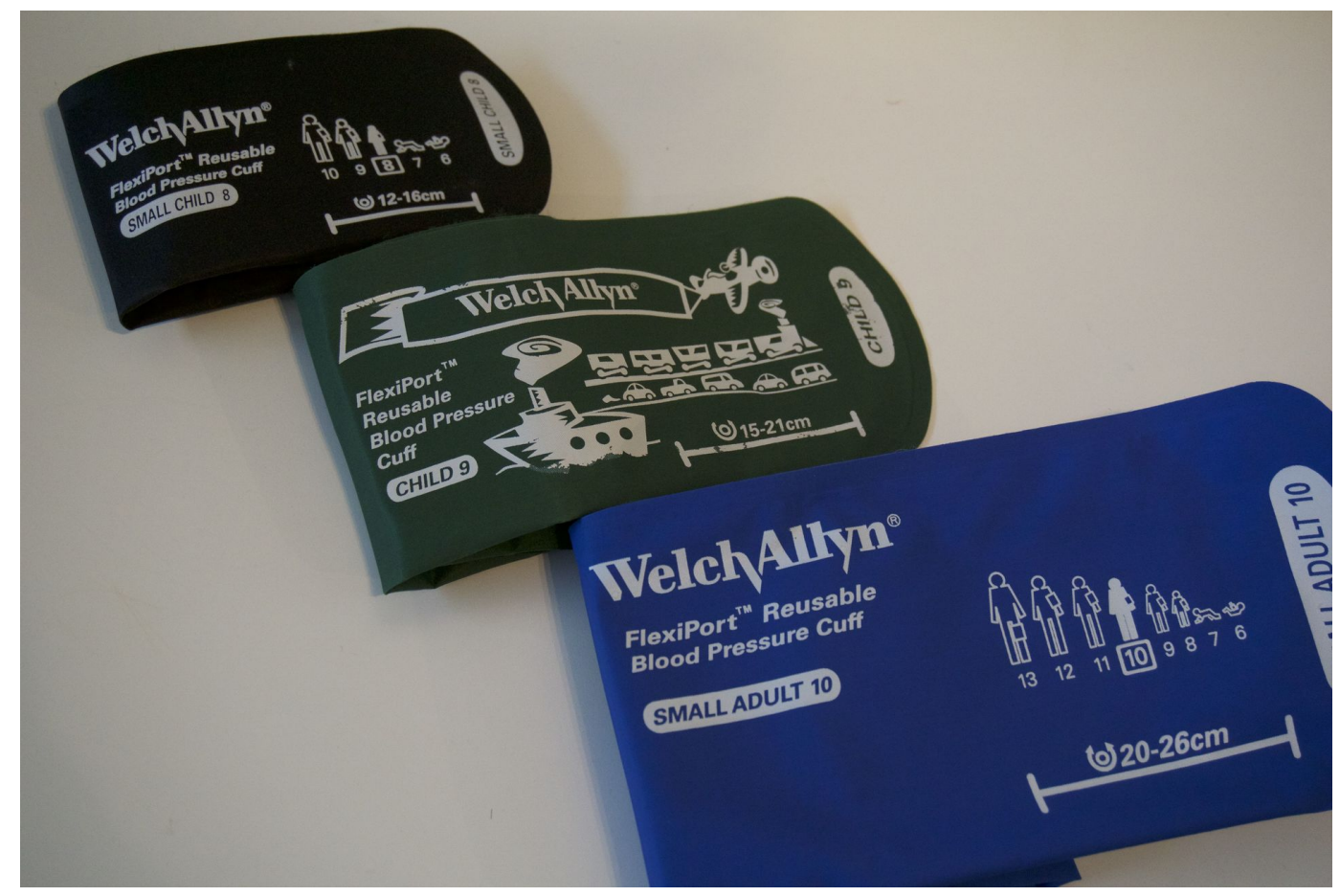

VELG RIKTIG: Dersom størrelsen på armen passer med to mansjetter, skal den største velges fordi en for liten mansjett kan overestimere mer enn en for stor mansjett kan underestimere. Foto: Privat

Dersom en passelig mansjett ikke er tilgjengelig, er det teknisk sett mulig å måle BT på underarmen med stetoskopet over arteria radialis $(3,11)$. Målinger på underarmen er rapportert å være i gjennomsnitt 3 mmHg høyere enn målinger på overarmen, både for SBT og DBT (12).

\section{Den som måler}

Pickering og medarbeidere kaller målepersonen den mest kritiske faktoren for nøyaktig BT-måling og hevder at observatørfeil er den største ulempen ved auskultatorisk metode (3). En av de vanligste feilene som blir gjort, er å runde av det målte BT til nærmeste $10 \mathrm{mmHg}$ i stedet for nærmeste $2 \mathrm{mmHg}$, som er anbefalt (3). Når kun 4 mmHg avgjør om et barn er prehypertensivt eller hypertensivt (1), er en avrunding til nærmeste 10 mmHg svært lite gunstig.

\section{三 «Målepersonen er den mest kritiske faktoren for nøyaktig blodtrykksmåling.»}


For å utføre korrekt BT-måling kreves god teknikk, bruk av et kalibrert måleapparat og riktig mansjettstørrelse, kunnskap om faktorer som kan påvirke målingen, evne til å instruere barnet og korrekt journalføring av måleresultatene (3). Dette krever at sykepleiere ikke bare blir riktig opplært og trenet i BTmåling, men også at de holder teknikk og kunnskap om BT-måling på barn ved like (3).

\section{Auskultatorisk måling}

Aneroide sphygmomanometre inneholder mekaniske deler som tannhjul, skruer og fjærer, som krever at de håndteres forsiktig. Både røff og dagligdags bruk kan gå ut over apparatets nøyaktighet (13). I tillegg blir de mindre nøyaktige med tiden og skal derfor kalibreres mot et kvikksølvmanometer hver sjette måned (13). Dette gjøres som regel på en medisinsk-teknisk avdeling på sykehus, og kan enkelt systematiseres ved å markere apparatene med når de sist ble kalibrert, og når de skal kalibreres igjen. Dessverre etterleves dette sjelden.

En studie har sammenliknet BT-målinger utført med både kvikksølvmanometer og aneroide sphygmomanometre på barn og funnet at DBT hadde en tendens til å underestimeres ved aneroide målinger. Dog ble ikke dette vurdert å ha klinisk betydning. Det var omtrent ingen forskjell i SBT mellom de to metodene (14).

Auskultatorisk metode utføres ved at BT-apparatet plasseres i øyehøyde til sykepleieren og ikke altfor langt unna, slik at riktige verdier lett kan leses av. Mansjetten plasseres på høyre overarm. Den er utstyrt med en markør som skal ligge over arteria brachialis, fortrinnsvis med noen centimeter klaring til innsiden av albuen, for å ha plass til stetoskopet (3). 
Hvis riktig valgt mansjettstørrelse fører til at stetoskophodet må være i kontakt med mansjetten, har ikke det noe å bety for målingen, men kan gi lyd som er forstyrrende for måleren (3). En kan da velge et stetoskop beregnet på nyfødte eller benytte bjellen på et vanlig stetoskop, som har mindre flate.

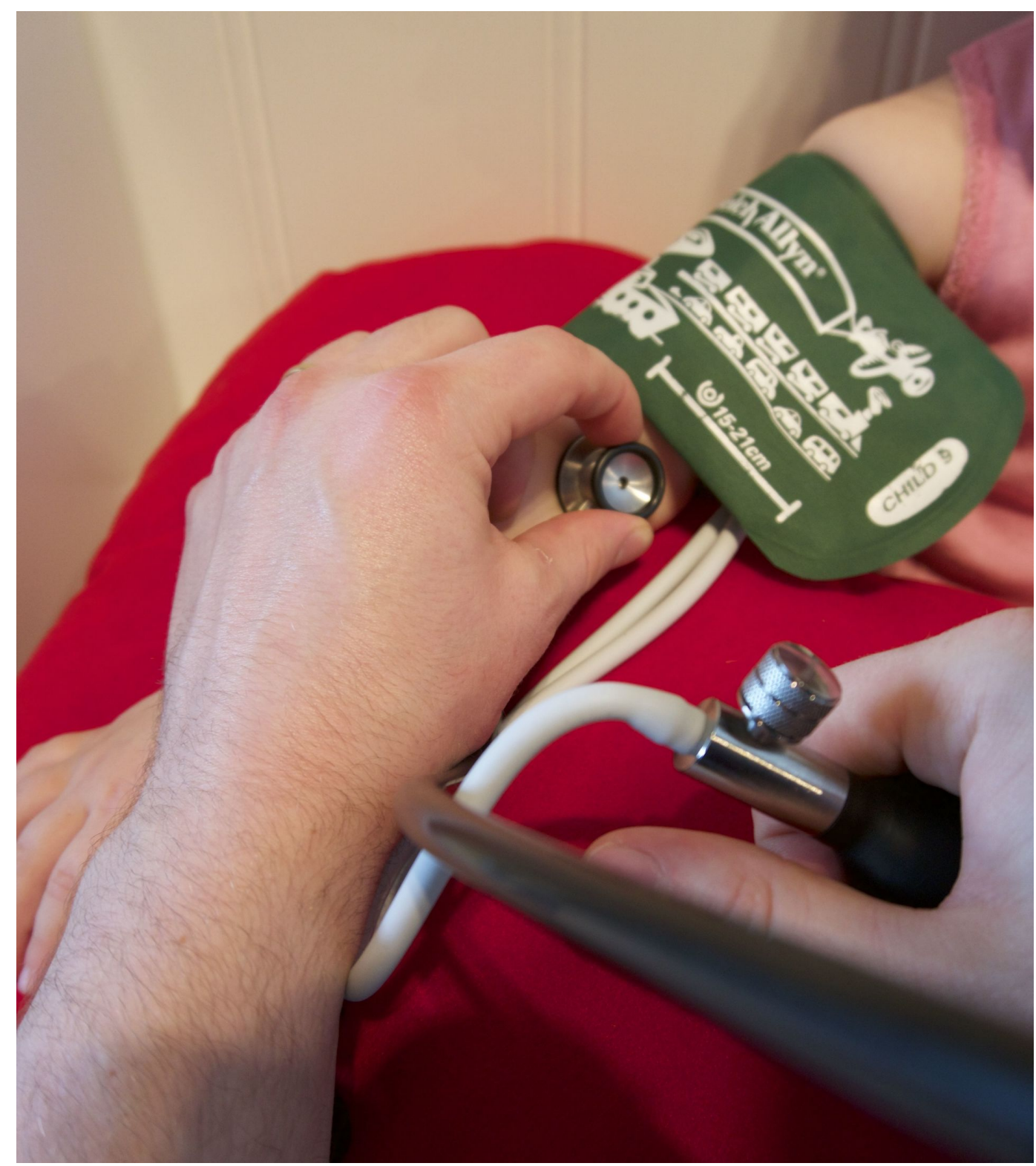

FOR BARN: Man kan bruke et stetoskop beregnet på nyfødte eller bjellen på et vanlig stetoskop, som har mindre flate. Foto: Privat 
Fordi barn kan oppleve det smertefullt dersom mansjetten pumpes opp for høyt, kan man begynne med å estimere SBT (3). Dette gjøres på følgende måte: Palper radialispuls og pump opp mansjetten til pulsen ikke lenger er følbar. Tallet på manometeret når pulsen opphører, er estimert SBT (3). Mansjetten pumpes opp til omtrent $30 \mathrm{mmHg}$ over estimert SBT, og deflateres med en hastighet på omtrent 2 mmHg per sekund eller per pulsslag dersom hjerterytmen er veldig langsom (3).

Hastigheten på deflateringen har en signifikant innvirkning på BT-målingen. Om den er raskere enn det anbefalte, kan det føre til underestimering av SBT og overestimering av DBT (3). SBT registreres når første pulsslag høres (K1), og DBT når lyden opphører (K5).

Nålen på manometeret begynner ofte å bevege seg med en takt forenlig med pulsslag før K1 høres. Dette skyldes trolig at like før så mye blod slipper gjennom den sammenklemte arterien at man hører K1, kan membranen i manometeret fange opp små endringer inne i mansjetten. Som nevnt brukes K1 til å registrere SBT, altså ikke nålens bevegelse.

\section{三 «Det kan være nyttig informasjon for den som skal vurdere blodtrykk, å vite om barnet var urolig, gråt, lekte, spiste eller liknende under målingen.»}

Hos noen barn kan Korotkoff-lyder høres helt ned til 0 mmHg. Da legges et lett trykk på stetoskophodet ved neste måling, og dersom K5 også da er nærmest eller lik 0 mmHg, skal K4 brukes til å registrere DBT $(1,3)$. Dersom K4 blir brukt, bør dette journalføres. 
BT måles minst to ganger med noen minutters mellomrom, og gjennomsnittet av målingene er barnets BT. Dersom det er $>5 \mathrm{mmHg}$ forskjell fra en måling til en annen, skal BT måles til en har to stabile målinger etter hverandre (3). Det kan være nyttig informasjon for den som skal vurdere BT, å vite om barnet var urolig, gråt, lekte, spiste eller liknende under målingen.

\section{Automatisk måling}

De fleste automatiske BT-apparater benytter seg av oscillometri. Metoden registrerer oscilleringer, svingninger i arterien mens den klemmes sammen av mansjetten. Punktet for maksimal oscillering registreres som middel-BT (MAP). SBT og DBT kalkuleres ut fra denne verdien (2, 3). Fordi oscilleringen er kortere hos barn enn hos voksne, økes risikoen for feilmålinger (2).

BT målt automatisk er i gjennomsnitt $10 \mathrm{mmHg}$ høyere enn auskultatoriske målinger for SBT og 5 mmHg høyere for DBT (7,). Europeiske og amerikanske retningslinjer er å måle BT minst tre ganger med noen minutters mellomrom ved hver kontroll for å minske faren for feilmåling $(1,2)$. Dette bekreftes i en studie fra 2016, hvor den største forskjellen fra måling en og to var 3,8 $\mathrm{mmHg}$ lavere for SBT og 3,3 mmHg lavere for DBT (15). Et unormalt høyt BT målt automatisk skal kontrolleres med auskultatorisk metode $(1,2)$.

De største fordelene med metoden er dens enkelhet og at den minsker faren for menneskelige feil $(3,16)$. Europeiske retningslinjer anbefaler å bruke et apparat som er blitt godkjent i en valideringsprosedyre (2). Svært få apparater har blitt validert for bruk på barn. En fullstendig oversikt over godkjente apparater kan sees på nettsiden til dabl Educational Trust (17). 
Målingen utføres ved at en passelig stor mansjett plasseres på barnets høyre overarm. Etter å ha forberedt og instruert barnet startes målingen. Den første målingen er ofte høy og skal strykes før en fortsetter med to målinger med minst 1 minutts mellomrom. Gjennomsnittet av de to siste målingene er barnets BT. Dersom forskjellen er $>5 \mathrm{mmHg}$, skal BT måles igjen inntil en har to stabile målinger etter hverandre (3).

\section{Referanseverdier}

Normalt BT hos barn bestemmes ut fra tre variabler: alder, høyde og kjønn (1). Det er utviklet persentilskjema som viser øvre grense for BT hos barn (1). Disse kan skrives ut i lommeformat fra nettsidene $t$ il National Heart, Lung, and Blood Institute (18) og er et godt hjelpemiddel for å kunne vurdere om et BT er normalt eller ikke. Nettsiden til Baylor College of Med icine (19) gir en grafisk fremstilling av om BT er normalt når en plotter inn barnets høyde, alder og kjønn samt det målte BT.

Referanseverdiene er basert på BT til over 70000 amerikanske barn målt auskultatorisk (1). Flere europeiske land, deriblant Norge (20-22), Sverige og Tyskland (23, 24), har utviklet egne referanseverdier for normalt BT hos barn i alderen to-atten år.

Likevel anbefaler European Society of Hypertension i sine retningslinjer for håndtering av høyt BT hos barn å bruke de amerikanske referanseverdiene, på grunn av den store populasjonen de er basert på (2). BT-verdier hos ungdom over 16 år skal vurderes ut fra normalverdier hos voksne, hvor høyt normalt BT er 130-139 / 85-89 mmHg og HT er $\geq 140 / 90$ mmHg (2).

\section{Hypertensjon}


Det antas at mellom 3 og 5 prosent av normalvektige barn har HT (25). Dette er en av de vanligste kroniske sykdomstilstandene hos barn. De vanligste årsakene til HT hos barn er nyresykdom, endokrine sykdommer og medfødt hjertefeil (26). Forhøyet BT hos barn kan føre til HT som voksen $(1,2,25)$ og dermed økt risiko for utvikling av hjerte- og karsykdommer og nyresvikt (3).

\section{三 «Barn kan ha såkalt white-coat hypertensjon, altså hypertensjon når blodtrykket måles av helsepersonell.»}

HT hos barn er definert som SBT og/eller DBT $\geq 95$ persentilen for kjønn, alder og høyde målt ved tre eller flere anledninger, med noen ukers mellomrom $(1,2)$. Viktigheten av flere målinger over tid er vist i to studier. I den ene falt prevalensen av HT fra 4,2 prosent ved første besøk til 1,1 prosent ved tredje besøk (27). I den andre hadde 11,4 prosent av barna HT ved første besøk mot 2,2 prosent ved tredje besøk (28).

Barn kan ha såkalt white-coat HT, altså HT når BT måles av helsepersonell, men normalt BT når målingen utføres utenfor sykehus (1). Tjuefiretimers ambulatorisk BT-måling eller hjemmemåling av BT er spesielt nyttig ved diagnostisering eller utelukking av white-coat HT, men også ved andre tilstander hvor en behøver mer informasjon om barnets BT (1).

Overvekt og fedme hos barn er et økende helseproblem og en viktig risikofaktor for utvikling av HT (29). Hos barn med overvekt og fedme er prevalensen av HT henholdsvis 4-11 prosent og 11-33 prosent (30).

\section{Konklusjon}


Alle barn fra tre års alder som følges opp eller behandles i sykehus, bør få målt sitt BT. Måling og vurdering av BT-verdier hos barn kan være utfordrende. For å oppnå korrekte målinger bør sykepleiere som arbeider med barn, ha kunnskap om faktorer som kan påvirke BT-måling. Den som utfører målingen, er kanskje den viktigste faktoren for korrekt BT-måling.

Feilaktig målt BT kan føre til at barnet utsettes for unødvendig utredning og behandling, og vil ofte medføre bekymringer hos barn og foreldre.

Automatisk BT-måling på barn kan gi feilaktig høye BT-verdier, da barn har kortere oscillering enn voksne. BT på barn bør derfor måles auskultatorisk eller med et automatisk apparat som er validert til bruk på barn. Høyt BT målt automatisk skal alltid kontrolleres med auskultatorisk metode.

\section{Referanser}

1. National High Blood Pressure Education Program Working Group. The fourth report on the diagnosis, evaluation, and treatment of high blood pressure in children and adolescents. Elk Grove Village, Illinois: American Academy of Pediatrics; 2004. 0031-4005 Contract No.: 2 part 3.

2. Lurbe E, Agabiti-Rosei E, Cruickshank JK, Dominiczak A, Erdine S, Hirth A, et al. 2016 European Society of Hypertension guidelines for the management of high blood pressure in children and adolescents. Journal of hypertension. 2016;34(10):1887-920. 
3. Pickering TG, Hall JE, Appel LJ, Falkner BE, Graves J, Hill MN, et al. Recommendations for blood pressure measurement in humans and experimental animals: Part 1: blood pressure measurement in humans: a statement for professionals from the Subcommittee of Professional and Public Education of the American Heart Association Council on High Blood Pressure Research. Hypertension. 2005;45(1):142-61.

4. Korotkov NS. Experiments for determining the efficiency of arterial collaterals. (Doktoravhandling.) PP Sovkine’s Press. 1910.

5. Lewis WH. The evolution of clinical sphygmomanometry. Bulletin of the New York Academy of Medicine. 1941;17(11):871-81.

6. Arafat M, Mattoo TK. Measurement of blood pressure in children: recommendations and perceptions on cuff selection. Pediatrics. 1999;104(3):e30.

7. Park MK, Menard SW, Yuan C. Comparison of auscultatory and oscillometric blood pressures. Archives of Pediatrics \& Adolescent Medicine. 2001;155(1):50-3.

8. Mo R. Konvensjonell blodtrykksmåling. Utposten. 2008;37(5):12-5.

9. Armstrong RS. Nurses' knowledge of error in blood pressure measurement technique. International Journal of Nursing Practice. 2002;8(3):118-26.

10. Chapman JA, Johnson JA. On the spot! Peer validation of BP measurement competence. Nursing Management. 2013;44(9):22-4. 
11. Schell K, Bradley E, Bucher L, Seckel M, Lyons D, Wakai S, et al. Clinical comparison of automatic, noninvasive measurements of blood pressure in the forearm and upper arm. American journal of critical care: an official publication, American Association of Critical-Care Nurses. 2005;14(3):232-41.

12. Taksande AM, Jadhav A, Nair J. Is it reliable to measure the forearm blood pressure in children? Journal of Family and Community Medicine. 2015;22(2):85-7.

13. Beevers G, Lip GY, O’Brien E. ABC of hypertension: blood pressure measurement. Part II conventional sphygmomanometry: technique of auscultatory blood pressure measurement. BMJ (Clinical research ed.). 2001;322(7293):1043-7.

14. Shah AS, Dolan LM, D’Agostino Jr. RB, Standiford D, Davis C, Testaverde L, et al. Comparison of mercury and aneroid blood pressure measurements in youth. Pediatrics. 2012;129(5):e1205-10.

15. Negroni-Balasquide X, Bell CS, Samuel J, Samuels JA. Is one measurement enough to evaluate blood pressure among adolescents? A blood pressure screening experience in more than 9000 children with a subset comparison of auscultatory to mercury measurements. Journal of the American Society of Hypertension. 2016;10(2):95-100.

16. Vidal E, Murer L, Matteucci MC. Blood pressure measurement in children: which method? which is the gold standard. Journal of Nephrology. 2013;26(6):986-92.

17. dabl Educational Trust. Blood pressure monitors - validations, papers and reviews 2014. Tilgjengelig fra: http://www.dableducational.org/ (nedlastet 25.05.2018). 
18. National High Blood Pressure Education Program Working Group on High Blood Pressure in Children and Adolescents. A pocket guide to blood pressure measurement in children. 2007. Tilgjengelig fra: https://www.nhlbi.nih.gov/files/docs/bp_child_poc ket.pdf (nedlastet 25.05.2018).

19. Baylor College of Medicine. Age-based pediatric blood pressure reference charts. 2010. Tilgjengelig fra: https://www.bcm.edu/bodycomplab/Fl ashapps/BPVAgeChartpage.html (nedlastet 25.05.2018).

20 Jackson LV, Thalange NK, Cole TJ. Blood pressure centiles for Great Britain. Archives of Disease in Childhood. 2007;92(4):298-303.

21. Menghetti E, Virdis R, Strambi M, Patriarca V, Riccioni MA, Fossali E, et al. Blood pressure in childhood and adolescence: the Italian normal standards. Study Group on Hypertension of the Italian Society of Pediatrics. Journal of Hypertension. 1999;17(10):1363-72.

22. Munkhaugen J, Lydersen S, Wideroe TE, Hallan S. Blood pressure reference values in adolescents: methodological aspects and suggestions for Northern Europe tables based on the NordTrondelag Health Study II. Journal of Hypertension. 2008;26(10):1912-8.

23. Schwandt P, Scholze JE, Bertsch T, Liepold E, Haas GM. Blood pressure percentiles in 22,051 German children and adolescents: the PEP Family Heart Study. American Journal of Hypertension. 2015;28(5):672-9.

24. Norman M. [New Swedish standard gives values for blood pressure in children - better opportunities to detect and treat children with hypertension]. Lakartidningen. 2015;112. 
25. Redwine KM, Acosta AA, Poffenbarger T, Portman RJ, Samuels J. Development of hypertension in adolescents with pre-hypertension. The Journal of Pediatrics. 2012;160(1):98-103.

26. Sinaiko AR. Hypertension in children. The New England Journal of Medicine. 1996;335(26):1968-73.

27. Sinaiko AR, Gomez-Marin O, Prineas RJ. Prevalence of «significant» hypertension in junior high school-aged children: the Children and Adolescent Blood Pressure Program. The Journal of Pediatrics. 1989;114(4 Pt 1):664-9.

28. Chiolero A, Cachat F, Burnier M, Paccaud F, Bovet P. Prevalence of hypertension in schoolchildren based on repeated measurements and association with overweight. Journal of Hypertension. 2007;25(11):2209-17.

29. Lo JC, Chandra M, Sinaiko A, Daniels SR, Prineas RJ, Maring B, et al. Severe obesity in children: prevalence, persistence and relation to hypertension. International Journal of Pediatric Endocrinology. 2014;2014(1):3.

30. Wirix AJ, Verheul J, Groothoff JW, Nauta J, Chinapaw MJ, Kist-van Holthe JE. Screening, diagnosis and treatment of hypertension in obese children: an international policy comparison. Journal of Nephrology. 2017;30(1):119-25. 